\title{
Additional TCRV $\beta$ primers and minor method modifications improve detection of clonal T-cell populations by RT-PCR
}

Department of Haematology, Derriford Hospital, Plymouth PL6 8DH C Lynas

Department of Haematology, Taunton and Somerset Hospital, Taunton, Somerset TA1 5DA D Howe

Correspondence to: Dr C Lynas.

\author{
C Lynas, D Howe
}

\begin{abstract}
The TCRVB RT-PCR method for detection of clonal populations of $T$ cells which we described previously could not detect clones that used certain variable (V) $\beta$ region families. V $\beta 2,4,8.3$, and 18 had insufficient homology with the original consensus $V$ region primer. Two new primers have been designed which work well and are able to amplify from V $\beta$ families previously undetectable by this RTPCR. In addition, minor alterations to the cDNA synthesis and gel analysis of the PCR products make the results even easier to interpret. All the Diversity/ Joining $(D / J)$ region primer combinations except for D2/J2 have been omitted, and terminating the reverse transcription by heating prior to PCR greatly improves amplification with these primers. Use of $8 \%$ and/or $10 \%$ polyacrylamide gels increases clarity. Inclusion of the modifications described will reduce false reporting of patients as having a polyclonal T-cell population.
\end{abstract}

(F Clin Pathol: Mol Pathol 1997;50:53-55)

Keywords: RT-PCR; T lymphocyte clone; T cell receptor $\beta$ chain rearrangement.

The method we described originally ${ }^{1}$ for the detection of clonal T-cell populations was a reverse transcription (RT) PCR assay which amplified across various portions of the T-cell receptor (TCR) $\beta$ variable-diversity-joiningconstant region (V-D-J-C) junction. TCR $\beta^{\star}$ rearrangements give rise to different size junction fragments so the PCR product from a polyclonal patient is a 3 base pair (bp) ladder of bands derived from these different rearrangements. In the presence of a T-cell clone one, and sometimes two, of these bands will be over-represented.

The primers we used include the consensus $\mathrm{V} \beta, \mathrm{D} \beta$, and $\mathrm{J} \beta$ primers described by $\mathrm{McCa}-$ rthy et al. ${ }^{2}$ All $\mathrm{J} \beta$ regions and both $\mathrm{D} \beta$ regions have sufficient homology to these primers to allow amplification but, as McCarthy et al point out, not all $\mathrm{V} \beta$ families will be amplified by the consensus primer for this region. Published V $\beta$ sequences confirmed that the

^For continuity with our original paper, we have continued with the old style nomenclature for the TCR. However, it should be the old style nomenclature for the TCR. However, it should be noted that TCRV $\beta$ is now consensus $\mathrm{V}$ primer would not be capable of amplifying $\mathrm{V} \beta 2,4,8.3$, or $18(\mathrm{~V} \beta 26$ onwards are now known to be pseudogenes ${ }^{3}$ ). cDNA sequences described by Concannon et $a l^{4}{ }^{4}$ which we used originally, suggested that the primer may not amplify V $\beta 13.2$ and 11.1, although this was not supported by genomic sequences (GenBank accession number L36092 and ${ }^{3}$ ) (table 1). Since 1991, when McCarthy et al devised their primers, many more $\mathrm{V} \beta$ families and new members of known families have been discovered. ${ }^{35-9}$

The aim of this study was to clarify which $V \beta$ segments had insufficient homology to the consensus $\mathrm{V}$ region primer for amplification and to design new primers to detect these $\mathrm{V}$ regions. Several other minor modifications further increase clarity of the PCR product ladders on the gels and hence aid interpretation.

\section{Methods}

PCR with the original $\mathrm{V} / \mathrm{C}, \mathrm{V} / \mathrm{J} 1$ and $\mathrm{V} / \mathrm{J} 2$ primers ${ }^{1}$ was performed on RNA from two patients known to have $\mathrm{T}$-cell clones that use $\mathrm{V} \beta$ 13.2.

Two new primers were designed to detect V $\beta 2 / V \beta 4$ or $V \beta 18 / V \beta 8.3$ using Primer Designer (Scientific and Educational Software) (table 1). They were placed in a similar relative position to the consensus $\mathrm{V}$ primer (16 and 8 bases upstream of $\mathrm{V}_{\text {concensus }}$, respectively) so that when included in a multiplex PCR, they would give PCR products in the same size range as seen with the consensus primer. The new primers were optimised to reduce secondary structure and their propensity to form dimers with the other primers present in a multiplex PCR.

The PCR mixtures were as described in our previous report, ${ }^{1}$ but now also contained $100 \mathrm{ng}$ of each of the new V $\beta$ primers. The effect of including these extra primers was investigated using RNA from two patients with a known $\mathrm{V} \beta 2$ clone and $\mathrm{KT} 1$, a V $\beta 18$ cell line. KT1 RNA was mixed at a ratio of $1: 15$ with RNA from a polyclonal patient prior to reverse transcription. All templates were amplified in the presence and absense of the new primers.

We investigated whether destroying the reverse transcriptase by heating after cDNA synthesis, as described in other RT-PCR protocols, ${ }^{1011}$ improves the results. Duplicate samples of RNA from a known polyclonal patient and one with a T-cell clone were reverse transcribed for one to two hours as described 
Table 1 V region primer homology

\begin{tabular}{|c|c|c|}
\hline$V \beta$ family & Primer sequence & Match \\
\hline & $\begin{array}{c}V_{\text {consensus }} \text { primer sequence } \\
5 \text {-tgt ayc tct gtg cca gca g-3' }\end{array}$ & \\
\hline $\mathrm{V} \beta 13.2$ (cDNA) & TGT AC $t$ TCT GTG CCA GCA $a$ & $17 / 19^{\star}$ \\
\hline $\mathrm{V} \beta 13.2$ (genomic) & TGT AC $t$ TCT GTG CCA GCA G & $18 / 19$ \\
\hline V $\beta 11.1$ (cDNA) & $a$ GT ACC TCT GTG CCA GCA $t$ & $17 / 19^{\star}$ \\
\hline V $\beta 11.1$ (genomic) & $\begin{array}{c}\text { aGT ACC TCT GTG CCA GCA G } \\
\text { V } \beta 2 / 4 \text { primer sequence } \\
\text { 5'-cet gaa gac agc agc wtm ta-3' }\end{array}$ & $18 / 19$ \\
\hline V $\beta 2.1$ (genomic) & CCT GAA GAC AGC AGC TTC TA & $20 / 20$ \\
\hline V $\beta 4.1$ (genomic) & $\begin{array}{l}\text { CCT GAA GAC AGC AGC ATA TA } \\
\text { V } \beta 18 / 8.3 \text { primer sequence } \\
5^{\prime}-\text { ttc agc tgc gta ttt ctg tg-3' }\end{array}$ & $20 / 20$ \\
\hline $\mathrm{V} \beta 18.1$ (genomic) & TTC $g$ GC $a$ GC $t$ TA TTT CTG TG & $17 / 20$ \\
\hline V $\beta 8.3$ (genomic) & $c$ TC AGC TG $t g$ TA TTT $t$ TG TG & $16 / 20$ \\
\hline
\end{tabular}

cDNA sequences from Concannon et al. ${ }^{4}$

Genomic sequences from GenBank, accession number L36092.

$\mathrm{Y}=\mathrm{C}+\mathrm{T} ; \mathrm{W}=\mathrm{A}+\mathrm{T} ; \mathrm{M}=\mathrm{A}+\mathrm{C}$

Published V $\beta$ sequences are shown in upper case where they match the primer, in lower case italics where they do not, and bold and lower case where there is a 3 ' mismatch.

^A 3' base mismatch is unlikely to allow amplification.

previously. ${ }^{1}$ One sample for each patient was then heated to $95^{\circ} \mathrm{C}$ for five minutes and centrifuged briefly. All cDNA samples were then diluted with $100 \mu$ l water; $4 \mu \mathrm{l}$ of this cDNA solution was used as the template in each PCR reaction.

The PCR protocol had to be amended as, since obtaining a licence, SuperTaq (HT Biotechnology, Cambridge, UK) is much more dilute. Taq polymerase from yet more manufacturers was also tested.

We investigated the use of different strength polyacrylamide gels. All products were run on the same $10 \%$ polyacrylamide gel at $10 \mathrm{~mA}$, the $\mathrm{V} / \mathrm{C}$ reactions for 90 minutes prior to loading the other reactions and running for a further 90 minutes. Alternatively, the V/C amplification products were run on an $8 \%$ gel at $10-15 \mathrm{~mA}$ for $60-90$ minutes.

\section{Results}

A brighter band indicative of the presence of a $T$-cell clone was visible in the polyclonal ladder of the patient known to have a V $\beta 13.2$ clone when the cDNA was amplified using the original PCR mixtures (fig 1, lane 7) which included only the $\mathrm{V}_{\text {consensus }}$ primer. The two patients with T-cell clones using V $\beta 2$ seemed to be polyclonal when amplified with the original PCR mixtures (fig 1, lanes 4 and 6). Neither could these primer mixtures detect the presence of KT1 V 18 RNA in a mixture with polyclonal RNA (fig 1, lane 1). However, when the new primers were included in the reactions, the V 32 clones (lanes 3 and 5) and KT1 RNA (lane 2) were detected easily. Results with the V/C primer mixture are shown, but the difference was equally obvious with the $\mathrm{V} / \mathrm{J}$ reactions.

Heating the cDNA to $95^{\circ} \mathrm{C}$ after cDNA synthesis to terminate the reaction produced a notable improvement in the results with the D2/J2 primer combination (fig 2, lanes 3-6). The bright primer-dimer band (fig 2, lanes 3 and 5) disappeared and PCR product in the expected size range became clearly visible. However, there was no obvious difference in the PCR results using $\mathrm{V} / \mathrm{C}, \mathrm{V} / \mathrm{J} 1$ or $\mathrm{V} / \mathrm{J} 2$ primer combinations (fig 2 , lanes 1 and 2 ) and no

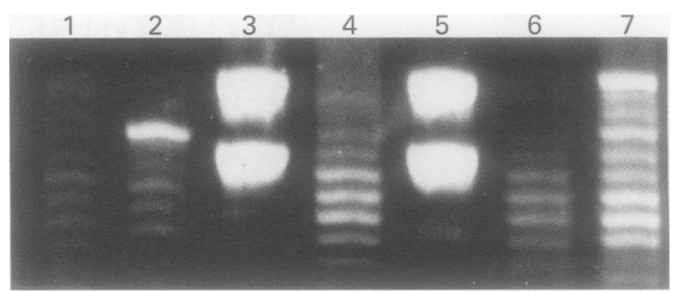

Figure 1 Various templates amplified using the $V_{\text {consensus }} / C$ primers with and without the inclusion of the VB2/4 and $V \beta 18 / 8.3$ primers (see table below).

\begin{tabular}{lll}
\hline Lane & Template $R N A$ & $V \beta$ primers used \\
\hline 1 & Polyclonal/KT1 mixture & Consensus only \\
2 & $\begin{array}{l}\text { Polyclonal/KT1 mixture } \\
\text { Consensus, V } \beta 2 / 4 \text { and } \\
\text { V } \beta 18 / 8.3\end{array}$ \\
3 & $\begin{array}{l}\text { Patient A with known } \\
\text { Consensus, V } \beta 2 / 4 \text { and }\end{array}$ & V $\beta 18 / 8.3$ \\
4 & $\begin{array}{l}\text { Patient A with known } \\
\text { V } \beta 2 \text { clone }\end{array}$ & Consensus only \\
5 & $\begin{array}{l}\text { Patient B with known } \\
\text { V } \beta 2 \text { clone }\end{array}$ & Consensus, V $\beta 2 / 4$ and \\
6 & $\begin{array}{l}\text { Patient B with known } \\
\text { V } \beta 2 \text { clone }\end{array}$ & Consensus only \\
7 & $\begin{array}{l}\text { Patient with known } \\
\text { V } \beta 13.2 \text { clone }\end{array}$ & Consensus only \\
& &
\end{tabular}

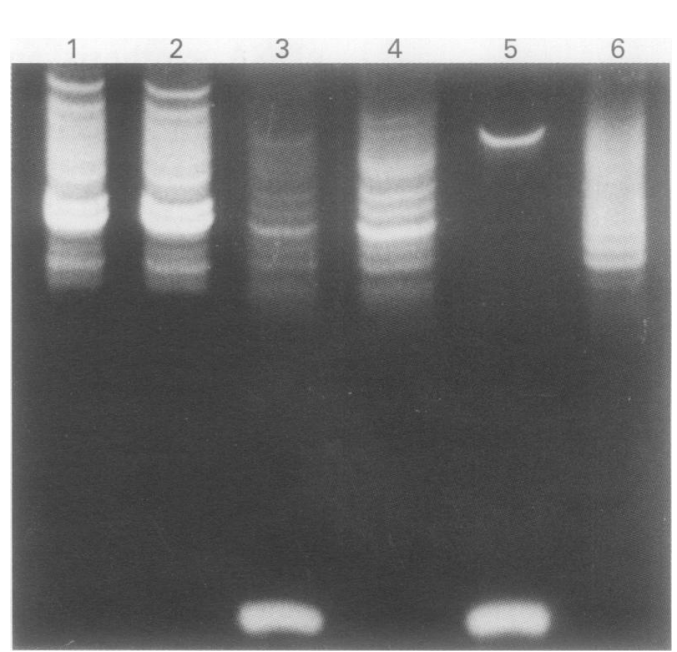

Figure 2 Effect of heating $c D N A$ to $95^{\circ} \mathrm{C}$ at the end of synthesis (see table below).

\begin{tabular}{|c|c|c|c|}
\hline Lane & Template RNA & Primers used & $c D N A$ heated \\
\hline 1 & $\begin{array}{l}\text { Patient A, known } \\
\text { T-cell disease }\end{array}$ & All $\mathrm{V} \beta$ and $\mathrm{J} 2$ & No \\
\hline 2 & $\begin{array}{l}\text { Patient A, known } \\
\text { T-cell disease }\end{array}$ & All $V \beta$ and $J 2$ & Yes \\
\hline 3 & $\begin{array}{l}\text { Patient A, known } \\
\text { T-cell disease }\end{array}$ & $\mathrm{D} 2 / \mathrm{J} 2$ & No \\
\hline 4 & $\begin{array}{l}\text { Patient A, known } \\
\text { T-cell disease }\end{array}$ & $\mathrm{D} 2 / \mathrm{J} 2$ & Yes \\
\hline 5 & Patient B, polyclonal & $\mathrm{D} 2 / \mathrm{J} 2$ & No \\
\hline 6 & Patient B, polyclonal & $\mathrm{D} 2 / \mathrm{J} 2$ & Yes \\
\hline
\end{tabular}

primer-dimer band was visible in any of these reactions.

Repeated use of the full range of $\mathrm{D} / \mathrm{J}$ primer combinations ${ }^{1}$ showed that there was nothing to be gained by using them all. D1/J1 invariably did not work at all, and D1/J2 produced exactly the same result as $\mathrm{D} 2 / \mathrm{J} 2$, although frequently not so bright (results not shown). We now use the D2/J2 primer combination for detection of partial rearrangements and confirm any positive results with a TCR $\gamma$ PCR.

All of the sources of Taq polymerase tested so far worked well: $0.25 \mu$ of enzyme was sufficient with both the new concentration Super- 
Taq and Taq polymerase from other manufacturers. Most of the results shown here were actually produced using TaKaRa $r$ Taq (Severn Biotech, Kidderminster, UK).

The results produced using a $10 \%$ gel were superior to those on a $12 \%$ gel, particularly for the $\mathrm{V} / \mathrm{C}$ product for which the lane tended to narrow during the extended run necessary to separate the polyclonal bands. However, the best results for the $\mathrm{V} / \mathrm{C}$ product were produced on $8 \%$ gels (for example, fig 1 ).

\section{Discussion}

Although published sequences for V $\beta 13.2$ and 11.1 are at variance (table 1 ), our results show that the consensus $V \beta$ primer is capable of amplifying V $\beta 13.2$. Rowen's genomic sequences (unpublished, GenBank accession number L36092) suggest that this should be possible, and that V $\beta 11.1$ would also be amplified by the consensus $\mathrm{V}$ primer. It is most likely that the 3' discrepancies in the cDNA sequences of Concannon $e t a l^{4}$ which suggested the consensus $\mathrm{V} \beta$ primer would not amplify $\mathrm{V} \beta 11.1$ and 13.2 arise from nibbling and insertions at junctions during rearrangement. ${ }^{12}$ It is also possible that such nibbling in vivo could destroy primer homology and lead to false reporting of monoclonal patients as polyclonal. We have considered moving the $\mathrm{V}$ region primer further from the $3^{\prime}$ end to avoid this possibility. However, it would be necessary to move a long way $5^{\prime}$ of the current primer position to find another region of high homology between the different V $\beta$ families, and the consequent, much larger PCR product would be much harder to analyse for the presence of a clonal population. It would undoubtedly be necessary to run SSCP gels to distinguish the clone on the basis of sequence as well as size. Our experience of this kind of analysis for TCR $\gamma$ suggests that it might be less sensitive than our current method.

All V $\beta$ sequences reported since McCarthy designed the $V \beta$ consensus primer, which we use, are either pseudogenes (V $\beta 26$ and above) or homologous to this primer, so only V $\beta 2,4$, 8.3 , and 18 remained undetectable. However, our new primers have been shown to amplify both V $\beta 2$ and V $\beta 18$. On the basis of sequence information, it is reasonable to anticipate that they will also amplify $V \beta 4$ and $V \beta 8.3$, but we have been unable to obtain any suitable samples to confirm this.

It is difficult to explain why heating the cDNA prior to PCR only seemed to affect the efficiency of amplification with D2/J2. Presence of residual reverse transcriptase activity in cDNA used as PCR template is known to inhibit Taq polymerase, ${ }^{13}$ and promote accumulation of primer-dimers. ${ }^{14}$ Our observations are unlikely to have been caused by direct inhibition or we would expect poor results with all primer combinations. We do see notable primer-dimer accumulation with the D2/J2 primers in the presence of active reverse transcriptase, but computer analysis does not suggest that this primer pair is any more likely to form dimers than the other pairs. Chumakov $^{14}$ suggested that reverse transcriptase may act by adding nucleotides to the 3 ' end of primers, altering their sequence and specificity. Certainly, the specificity of the D2 primer is likely to be less than that of the other primers, even without interference from reverse transcriptase as the $D$ region can be extensively modified during rearrangement by nibbling and $\mathrm{N}$ region insertions at both ends. ${ }^{12}$ Presence of active reverse transcriptase may promote dimer formation rather than priming of Taq activity. However, by heating the cDNA we should be able to improve detection of patients with partially rearranged T-cell clones.

TCRV $\beta$ PCR is superior to Southern blotting for the detection of patients with T-cell clones. ${ }^{1}$ The inclusion of the two new V $\beta$ primers, and the other modifications we have made, will further improve detection by PCR.

We are indebted to Dr E Hodges for supplying RNA from the patients with clones using TCRV 32 , to Dr AW Langerak for RNA from patients with clones using TCRV $\beta 13.2$ and to Professor JM van Dongen for the KT1 RNA. DH is supported by the Musgrove Leukaemia Group, Somerset.

1 Lynas C, Howe D, Copplestone JA, Johnson SAN, Phillips MJ. A rapid and reliable PCR method for detecting clonal T cell populations. F Clin Pathol: Mol Biol 1995;48:M101-

2 McCarthy KP, Sloane JP, Kabarowski JHS, Matutes E, Wiedemann LM. The rapid detection of clonal T-cell proliferations in patients with lymphoid disorders. Am f Pathol 1991;138:821-8.

3 Arden B, Clarke SP, Kabelitz D, Mak TW. Human T-cell receptor variable gene segment families. Immunogenetics receptor variable

4 Concannon P, Pickering LA, Kung P, Hood L. Diversity and structure of human $\mathrm{T}$-cell receptor $\beta$-chain variable region genes. Proc Natl Acad Sci USA 1986;83:6598-602.

5 Hansen T, Qvigstad E, Lundin KEA, Thorsby E. Sequences of four previously undescribed human T-cell receptor $\beta$ chain variable genes. Tissue Antigens 1991;38:99-103.

6 Ferradini L, Roman-Roman S, Azocar J, Michalaki H, Triebel F, Hercend T. Studies on the human T cell receptor $\alpha / \beta$ variable region genes II. Identification of four additor $\alpha / \beta$ variable region genes II. Identification of four

7 Gomolka M, Epplen C, Buitkamp J, Epplen JT. Novel members and germline polymorphisms in the human T-cell receptor V $\beta 6$ family. Immunogenetics 1993;37:257-65.

8 Robinson MA. The human T cell receptor $\beta$-chain gene complex contains at least 57 variable gene segments. $f$ Immunol 1991;146:4392-7.

9 Slightom JL, Siemieniak DR, Sieu LC, Koop BF, Hood L. Nucleotide sequence analysis of $77.7 \mathrm{~kb}$ of the human $\mathrm{V}_{\beta}$ T-cell receptor gene locus: Direct primer-walking using cosmid template DNAs. Genomics 1994;20:149-68.

10 Cross NCP, Melo JV, Feng L, Goldman JM. An optimized multiplex polymerase chain reaction (PCR) for detection of multiplex polymerase chain reaction (PCR) for detection of BCR-ABL fusion mRN

11 Downing JR, Head DR, Curcio-Brint AM, Hulshof MG, Motroni TA, Raimondi SC, et al. An AML1/ETO fusion transcript is consistently detected by RNA-based polymerase chain reaction in acute myelogenous leukemia containing the $(8 ; 21)(\mathrm{q} 22 ; \mathrm{q} 22)$ translocation. Blood 1993;81: 2860-5.

12 Lieber MR. The mechanism of V(D)J recombination: A balance of diversity, specificity, and stability. Cell 1992;70: 873-6.

13 Fehlman C, Krapf R, Solioz M. Reverse transcriptase can block polymerase chain reaction. Clin Chem 1993;39:368-

14 Chumakov KM. Reverse transcriptase can inhibit PCR and stimulate primer-dimer formation. PCR Methods Appl 1994;4:62-4. 